\title{
In vitro Proliferation of Chick Primordial Germ Cells Co-cultured with Germinal Ridge Stroma Cells
}

\author{
Ryou Fukushima and Noboru Fujihara \\ Laboratory of Animal Reproductive Physiology, Division of Animal Resource \\ Science, School of Agriculture, Graduate School Kyushu \\ University, Fukuoka 812-8581 Japan
}

\begin{abstract}
In order to develop the technique for in vitro culture of chicken primordial germ cells obtained from circulating embryonic blood vessels (cPGCs), participation of feeder cells and some of growth factors was examined. In this experiment, Dulbecco's MEM (DMEM) mixed with Ham's F12 was used in combination with some kind of cell growth factors such as chicken stem cells factor (SCF), human leukemia inhibitory factor (LIF), human basic fibroblast growth factor (bFGF) and chicken insulin-like growth factor (IGF-1). In the present study, chicken embryos incubated for 5, 6 and 7 days were subjected to the isolation of stroma cells from germinal ridges. These stroma cells isolated from germinal ridge which were used as feeder cells, were divided into two parts, left side stroma cells (L-GRSCs) and right ones (R-GRSCs). The cPGCs were obtained by the filtration method from blood samples aspirated from extra-embryonic veins. The short-term (6 days) culture of cPGCs with L-GRSCs derived from 5 days embryos showed slightly increased proliferation of the cells, by around 1.7-2.3 times. Contrariwise, the co-culture of cPGCs with R-GRSCs did not bring about any increase of PGCs number compared with the case of L-GRSCs. On the one hand, the co-culture with both L- and R-GRSCs derived from 6 and 7 day embryos, resulting in the disappearance of the cells after 7 days of culture. In case of the long-term (30 days) culture with L- and R-GRSCs, the number of PGCs significantly $(\mathrm{P}<0.05)$ increased, showing 70 to 100 times increment. In these cases, no significant difference was observed between L- and R-GRSCs or among growth factors added. In addition to this, the PGCs cultured for 30 days formed a kind of cell clumps surrounded by the co-cultured GRSCs. The results obtained in this experiment suggest the possibility of proliferation of the PGCs outside the body by co-culturing with germinal ridge stroma cells derived from the 5 day embryos.
\end{abstract}

Key words : chicken, PGCs, in vitro culture, proliferation, germinal ridge stroma cells

\section{Introduction}

Chicken primordial germ cells (PGCs) have been thought to originate from central disk of area pellucida of developing embryos at stage X to XII (Eyal-Giladi and Kochav, 1976 ; Ginsburg and Eyal-Giladi, 1987 ; Kagami et al., 2000). Then the cells

Received : September 22, 2000 Accepted : December 14, 2000

Correspondence : Noboru Fujihara, Laboratory of Animal Reproductive Physiology, Division of Animal Resource Science, School of Agriculture, Graduate School Kyushu University, Fukuoka 812-8581 Japan TEL : +81-92-642-2940, FAX : + 81-92-642-2938 E-mail : nfujiha@agr.kyushu-u.ac.jp 
gradually move from epiblast to hypoblast layer of the germinal crescent region (GCR) of the primitive streak (Eyal-Giladi et al., 1981). The PGCs which gathered in the GCR enter the blood stream at the stage 10 (Hamburger and Hamilton, 1951) of embryonic development. After leaving the blood circulation at stage 16 to 17 , the PGCs migrate to the developing gonadal anlage at stage 26-28, around 2.5 day of incubation, and differentiate to ova or spermatozoa (Fujimoto et al., 1976 ; Kuwana, 1993).

It has been reported that blastodermal cells were used for producing germline chicken chimeras (Pettite et al., 1990 ; Kagami et al., 1995) and that the PGCs were also employed to transfer genetic information to next generation as one of the vectors for transgenic studies (Han et al., 1994a, b ; Naito et al., 1994 ; Ono et al., 1996 ; 1998).

Based on these several features of the chicken cells, including blastodermal or primordial germ cells, the latter cells may be superior in the production of transgenic chicken to the former ones. In this case, the establishment of in vitro culture systems of PGCs could be much more useful for improving reproductive efficiency of germline chicken chimeras. Unfortunately, only a little has so far been reported about successful culture of chicken PGCs outside the body.

On the one hand, it is well known that developing right and left side ovaries of chicks are asymmetrical in shape, exhibiting different size on right and left sides, resulting in the larger size for left side organ (Ukeshima and Fujimoto, 1991). It has also been reported that in the right ovary, the number of germ cells is smaller and the frequency of germ cell death is much higher than that in the left organ.

In the previous studies, the PGCs were reported to be proliferated by around 29 to 35 times for 17 days of culture with the GRSCs feeder cells (Yang and Fujihara, 1999 $\mathrm{a}, \mathrm{b})$.

Considering these findings, it is considered that difference between left or right side ovaries may affect in vitro proliferation of PGCs. In this experiment, therefore, the PGCs obtained from circulating blood stream were cultured outside the body together with the GRSCs divided into two parts, right and left sides, as feeder cells.

\section{Materials and Methods}

\section{Preparation of germinal ridge stroma cells from right and left sides}

Fertilized eggs obtained from White Leghorn or Rhode Island Red strains were incubated at $37^{\circ} \mathrm{C}$ under $60-70 \%$ humidity for 5,6 and 7 days until stage 24-26, 26-28 and 28-30, respectively. After a given period of incubation, embryos were stripped from the yolk, rinsed with calcium-magnesium free Dulbecco's phosphate buffered saline (PBS-) and transferred to 65-mm petri dishes coated with wax. The abdomen of the embryo was carefully peeled off with forceps to locate the primitive kidneys. Under the objective microscope, germinal ridges divided into two parts, left and right sides were separated from the kidneys and collected in a $1.5-\mathrm{m} l$ tube loaded with $1 \mathrm{~m} l$ of PBS-. Subsequently, these germinal ridges were digested with $0.25 \mathrm{mg} / \mathrm{m} l$ of collagenase at $37^{\circ} \mathrm{C}$ for $20 \mathrm{~min}$. The cell suspension was filtered through a cell strainer, 
washed twice with medium 199 with Hanks' salts containing with $10 \%$ fetal bovine serum (FBS) and cultured in DMEM (Gibco BRL, Grand Island, NY) mixed with Ham's F12 (Gibco BRL, Grand Island, NY) supplemented with 10\% FBS and 1\% penicillin-streptomycin (Gibco BRL, Grand Island, NY) in a 96 well plate at $37^{\circ} \mathrm{C}, 5 \%$ $\mathrm{CO}_{2}$ in air. Cell confluence took about 3 days.

Preparation of $\mathrm{cPGCS}$

Fertilized eggs obtained from White Leghorn or Rhode Island Red strains were incubated until stage 12-14 under the same conditions as described previously. Blood samples were collected from extra-embryonic vein of the embryos using fine glass pipette. The isolation of cPGCs from blood samples were conducted by filtration method (TAJIMA et al., 2000). In this experiment, filter membranes (NY 10-HC, Sefar Inc., Thal, Switzerland) which pore size was $10 \mu \mathrm{m}$ were used. Pooled blood samples were centrifuged at $1,000 \mathrm{rpm}$ for $5 \mathrm{~min}$. After removing the supernatant, the pellet was dispersed in $1 \mathrm{ml}$ of medium 199 with Hanks' salts. The cell suspension was filtrated by filter membranes, PGCs which diameter is around $14 \mu \mathrm{m}$ were left on filter. Then PGCs were tear off from filters and centrifuged at $1,000 \mathrm{rpm}$ for $5 \mathrm{~min}$. Collected cells were filtrated once again. The cells collected after the filtration were labeled with PKH26 red fluorescent cell linker kit (No PKH26-GL, Sigma Chemical Co., St. Louis, MO), the labeled cPGCs were selected with a micromanipulator and stored in growth medium added no growth factors. The rate of purification of cPGCs after the isolation was determined by counting red blood cells and cPGCs under the objective microscope. Culture of cPGCS

When feeder cells were confluent, the prepared cPGCs were seeded onto the feeder layer cultured in a medium containing several kinds of growth factors. The medium was changed every two days with fresh medium. On the present study, following growth factors were added; chicken SCF $100 \mathrm{ng} / \mathrm{ml}$, human LIF $20 \mathrm{ng} / \mathrm{ml}$, human $\mathrm{bFGF} 10 \mathrm{ng} / \mathrm{ml}$, and chicken IGF-I $10 \mathrm{ng} / \mathrm{ml}$. The LIF, bFGF and IGF-I were purchased from commercial source and SCF was a kind gift from Dr. M. Sakurai of the National Institute of Animal Health, Tsukuba, Japan. In the short-term culture, cells were kept for up to 5-6 days, two experimental groups were designed. In the long-term culture, the cells were maintained for 30 days. In this experiment, five trials were conducted in the combination with growth factors, Trial $1:$ SCF, Trial $2:$ SCF + LIF, Trial $3:$ LIF + bFGF + IGF-1, Trial $4:$ all kinds of growth factors, Trial 5 : control.

\section{Counting of cPGC number}

The PKH26-positive cells were directly counted everyday under the microscope equipped with a TE-FM Epi-fluorescent attachment. After 6 days of culture, direct cell count was impossible, since the GRSCs and cPGCs formed a kind of cell clumps. After 30 days of culture, the cell clumps were digested with $0.25 \%$ Trypsin-EDTA solution, and determining PKH26-positive cells. Following the treatments, the labeled cells in the cell clumps were observed under the confocal laser microscope (RCM-8000, Nikon, Tokyo). 


\section{Results}

An average percentage of PGCs harvested by the filtration method was $62.45 \pm$ $14.05 \%$ for 4 replicates. In the short-term (5-6 days) culture, the proliferation of cPGCs was promoted significantly $(p<0.05)$ by L-GRSCs derived from 5 days embryos more than R-GRSCs derived from the same embryos as 5 days of incubation (Figs. 1 a, b). The number of cPGCs tended to reduce when the cells were cultured with L- or R-GRSCs from 6 and 7 days embryos (Figs.1 c, d, e, f), resulting in that most of the
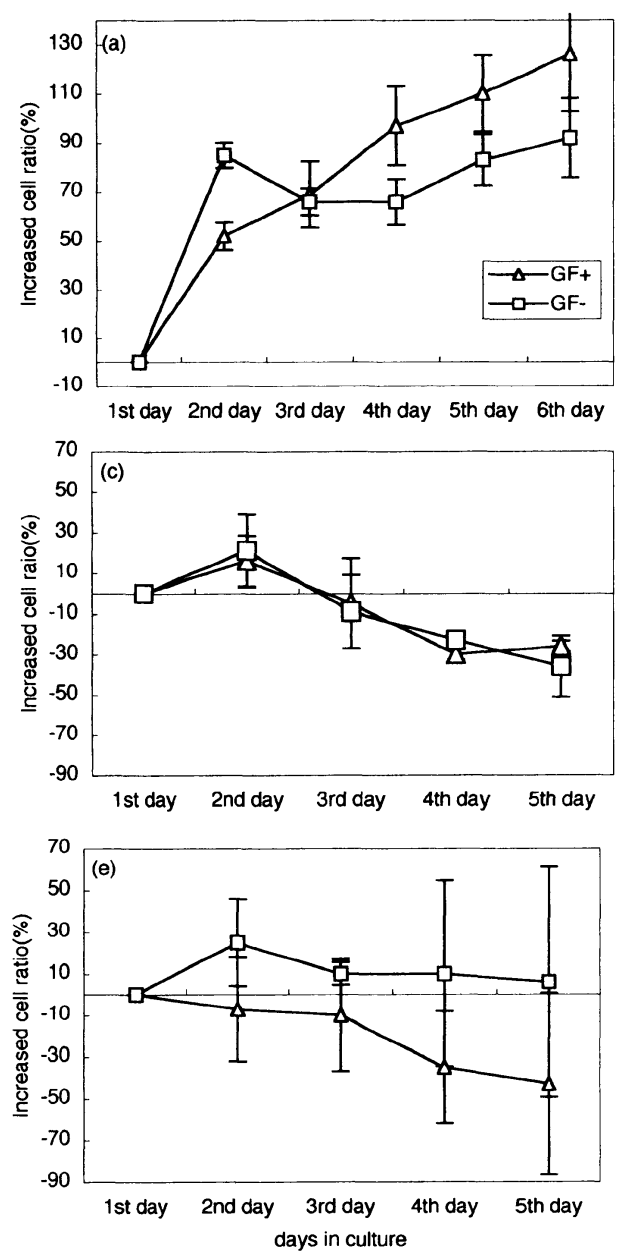
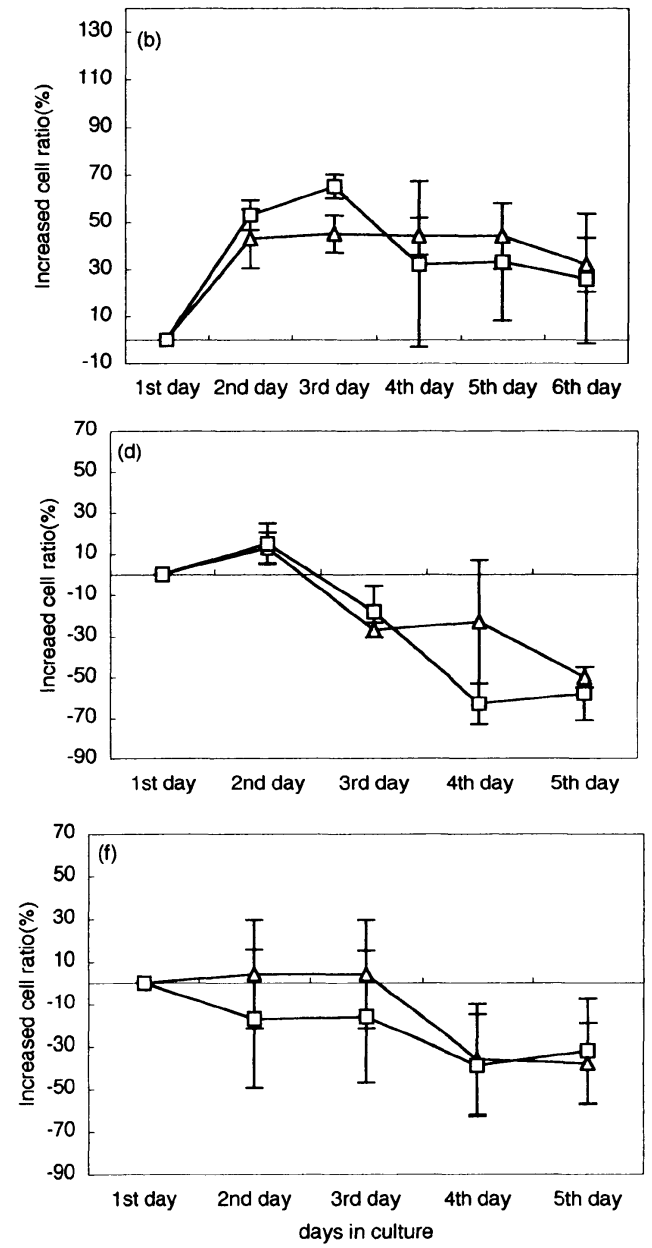

Fig. 1. The effect on short-term culture of cPGCs of germinal ridge stroma cells from embryos divided according to the developmental stages. Each group represents three replicates of tests.

cPGCs were cultured with growth factors $(\mathrm{SCF}+\mathrm{LIF}+\mathrm{bFGF}+\mathrm{IGF}-1)$ (triangle) or without growth factors (square) for 5 to 6 days, and counted. As feeder cells, left sides of germinal ridge stroma cells (L-GRSCs) (a), R-GRSCs (b) derived from 5 days chick embryos, L-GRSCs (c), R-GRSCs (d) from 6 days embryos, and L-GRSCs (e), R-GRSCs (f) from 7 days embryos were used. 

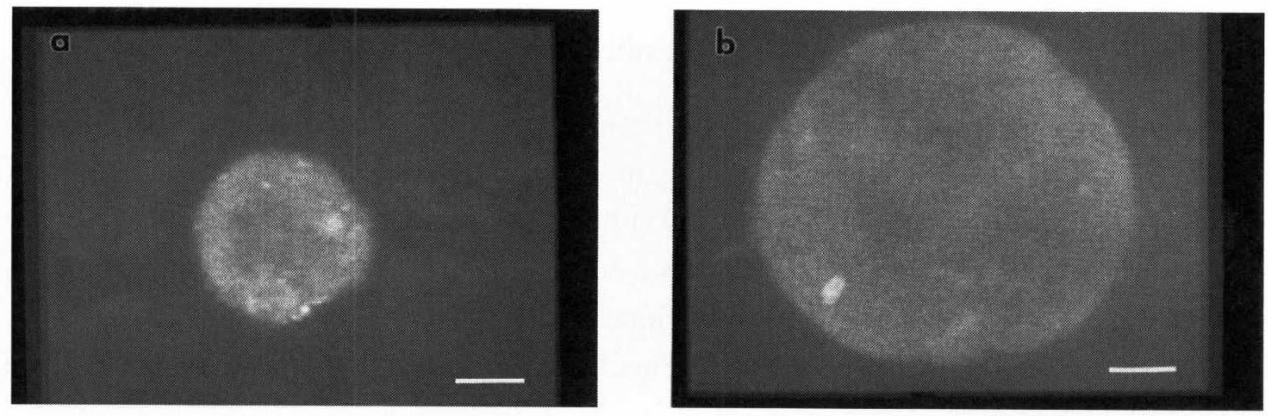

Fig. 2. Sections of cell clump after 30 days of culture observed under the confocal laser microscope.

Many PKH 26-positive cells were observed in cell clump co-cultured with cPGCs (a), no positive cells in clump without cPGCs (b). Scale bar is 20 $\mu \mathrm{m}$.

cells disappeared by the 7 days of culture (data not shown). The increasing rate of cPGCs number cultured in vitro was not significantly $(\mathrm{p}>0.05)$ different among of growth factors added to culture media.

The cPGCs co-cultured with L- and R-GRSCs derived from 5 days embryos survived for up to 30 days. In this experiment, cell clumps were formed with GRSCs, leading the active mitosis like the normal cell proliferation. In this case, cPGCs were engulfed gradually into developing cell clumps. After 30 days of culture, many PKH 26 positive cells were observed in the cell clumps under the confocal laser microscope (Fig.2), and the number of these cells increased by 70 to 100 times. Significant differences were not confirmed between L- and R-GRSCs or the combinations of growth factors $(\mathrm{p}>0.05)$.

\section{Discussion}

In the present experiments, the newly developed filtration method was used to isolate cPGCs from the blood samples of chicken embryos (Tajima et al., 2000), resulting in the rate of $62.4 \pm 14 \%$ for the PGCs obtained. In the previous studies, the Ficoll density gradient (6.3\% and16\% of Ficoll 400-DL, Sigma Chemical Co., St. Louis, MO) centrifugation method was employed (Yasuda et al., 1992), though an average percentage of cPGCs number was quite low, 9.84 $\pm 0.4 \%$ (Yang and Fujihara, 1999a). The present results suggest that the method of filtration could be much more superior to the previous method such as density gradient centrifugation using Ficoll. One of the advantages of filtration method is probably the unnecessarily of removing some other materials used for centrifugation and collecting the graded cells from the tubes.

On the other hand, it has been reported in the chicken that germ cells could proliferate dominantly in developing cortex of the left ovary compared with the medulla of right organ (Ukeshima et al., 1991). In our present experiments, especially in the short term (6 days) culture, the GRSCs derived from the left side of germinal ridge (L-GRSCs) of 5 days chicken embryos brought about significantly $(\mathbf{P}<0.05)$ higher 
rate of the cell proliferation in comparison with the R-GRSCs of the same day of culture (Figs. $1 \mathrm{a}, \mathrm{b}$ ). On the contrary, in the case of long-term (30 days) culture, the PGCs resided preferentially in the surface area rather than the central part of the cell clumps (Fig. 2 a). Even in this case, only the GRSCs derived from 5 days chicken embryos contributed to the formation of cell clumps.

Based on such findings as asymmetric development of left and right side of germinal ridges of chicken embryos, the present results may reflect some of the physiological mechanisms of gonadal development of chicken embryos. However, the results obtained from 30-day culture showed no significant difference between the Land R-GRSCs in the rate of proliferation of PGCs outside the body (Table 1).

This finding may be suggestive of disappearance of differential function of GRSCs after long-term culture of the cells, especially after the formation of cell clumps in vitro. Previous reports have demonstrated that the feeder cells from GRSCs participated in proliferating cPGCs by about 4.8 times and 35 times for 5 and 17 days of culture of the PGCs, respectively. Some of clear differences in the proliferation of PGCs outside the body would be caused by physiological dissimilarity between in vivo and in vitro situations. In the case of in vitro studies, any of physiological factors could not be involved in the function.

The results obtained from the present works may indicate that the PGCs could be formed a kind of cell clumps when the cells were co-cultured with the GRSCs derived from 5 days chicken embryos. These experiments may also be suggestive of creating

Table 1. In vitro proliferation of PGCs co-cultured for 30 days* with germinal ridge stroma cells derived from 5 -day chicken embryos

\begin{tabular}{|c|c|c|c|c|c|}
\hline \multirow[b]{2}{*}{ Trial No. } & \multicolumn{5}{|c|}{$\begin{array}{l}\text { Number of cPGCs cultured with cells derived from left side of } \\
\text { germinal ridge }\end{array}$} \\
\hline & 1 & 2 & 3 & 4 & 5 \\
\hline 1st day & 34.5 & 37.5 & 38 & 32 & 32.5 \\
\hline 30th day & 3419.3 & 3070.3 & 3599.3 & 3084 & 3338 \\
\hline \multirow[t]{2}{*}{ Rate } & 91.6 & 89.4 & 94.7 & 96.4 & 102.7 \\
\hline & \multicolumn{5}{|c|}{$\begin{array}{l}\text { Number of cPGCs cultured with cells derived from right side of } \\
\text { germinal ridge }\end{array}$} \\
\hline Trial No. & 1 & 2 & 3 & 4 & 5 \\
\hline 1st day & 34 & 32.7 & 38.7 & 28 & 29 \\
\hline 30 th day & 3196.7 & 3426.7 & 4335 & 2157 & 2916.7 \\
\hline Rate & 94 & 104.9 & 112.1 & 77 & 100.1 \\
\hline
\end{tabular}

* The cells were cultured for 30 days.

The number of cPGCs cultured in cell clump on L and R-GRSCs for 30 days.

Trial No. is the combination of growth factors. Trial $1: \mathrm{SCF}$, Trial $2: \mathrm{SCF}+\mathrm{LIF}$,

Trial $3: \mathrm{LIF}+\mathrm{bFGF}+\mathrm{IGF}-1$,

Trial $4: \mathrm{SCF}+\mathrm{LIF}+\mathrm{bFGF}+\mathrm{IGF}-1$, Trial $5:$ control

Each group represents three replicates of tests. 
germline chimera of chicken using the present new procedure for isolating PGCs and culturing the cells outside the body.

\section{Acknowledgements}

The authors are grateful for financial support provided in part by Grants-in-Aid for Scientific Research from the Japanese Ministry of Education, Science, Sports and Culture, Japan Society for the Promotion of Science (JSPS), Toyota Foundation, Sumitomo Foundation and Nissan Science Foundation. Appreciation is also extended to Dr. G. Q. YANG and Dr. T. KUWANA for their kindest guidance in the cultivation and the preparation of chicken PGCs in vitro, respectively. They also wish to thank Dr. M. SAKURAI for his generous gift of chicken SCF. The help supplied by Dr. H. FURUTA and Mr. T. FUJIOKA was greatly appreciated.

\section{References}

Chang IK, Tajima A, Chikamune T and Ohno T. Proliferation of chick primordial germ cells cultured on stroma cells from the germinal ridge. Cell Biology International, 19 : 143-149. 1995.

Eyal-Giladi $\mathbf{H}$ and Kochav S. From cleavage to primitive streak formation : a complementary normal table and a new look at the first stages of the development of the chick. Developmental Biology, 49 : 321-337. 1976.

Eyal-Giladi H, Ginsburg M and Fabarov A. Avian primordial germ cells are of epiblastic origin. Journal of Embryology \& Experimental Morphology, 65 : 139-147. 1981.

Fujimoto T, Ukeshima A and Kiyofuji R. The origin, migration and morphology of the primordial germ cells in the chick embryo. The Anatomical Record, $185: 139-154.1976$.

Ginsburg $\mathbf{M}$ and Eyal-Giladi $\mathbf{H}$. Primordial germ cells of the young chick blastoderm originate from the central zone of the area pellicida irrespective of the embryo-forming process. Development, $101: 209-219.1987$.

Hamburger V and Hamilton HL. A series of normal stages in the development of the chick embryo. Journal of Morphology, $88: 49-92.1951$.

Han JY, Shoffner RN and Guise KS. Gene transfer by manipulation of primordial germ cells in the chicken. Asian Australasian Journal of Animal Sciences, 7 : 427-434. 1994.

Han JY, Seo DS and Shoffner RN. Primordial germ cells in aves. Asian Australasian Journal of Animal Sciences, $7:$ 459-466. 1994.

Kagami H, Clark ME, Verrinder-Gibbins AM and Etches RJ. Sexual differentiation of chimeric chickens containing ZZ and ZW cells in the germline. Molecular Reproduction and Development, $42: 379-387.1995$.

Kagami H, Iwata J, Nakata A, Tagami T, Matsubara Y, Harumi T, Tachi C, Okabayashi H, Kashiwazaki N, Shino M and Naito M. Substantial evidence to localize the developmental origin of primordial germ cells in the chicken. Animal Science Journal, $71: 38-41.2000$.

Kuwana T. Migration of avian primordial germ cells toward the gonadal anlage. Development Growth and Differentiation, 35 : 237-243. 1993.

Naito M, Tajima A, Yasuda Y and Kuwana T. Production of germline chimeric chickens, with high transmission rate of donor-derived gametes, produced by transfer of primordial germ cells. Molecular Reproduction and Development, 39 : 153-161. 1994.

Ono T, Yokoi R and Aoyama H. Transfer of male or female primordial germ cells of quail into chick embryonic gonads. Experimental Animals, 45 : 347-352. 1996.

Ono T, Yokoi R, Maeda S, Nishida T and Aoyama $\mathbf{H}$. Transfusion of chick primordial germ cells into quail embryos and their settlement in gonads. Animal Science and Technology, 69 : 911-915. 1998.

Petitte JN, Clark ME, Liu G, Verrinder-Gibbins AM and Etches RJ. Production of somatic and germline chimeras in the chicken by transfer of early blastodermal cells. Development, 108 
: 185-189. 1990

Tajima A, Barbato GF, Kuwana T and Hammerstedt RH. Recovery of a genetically selected broiler line using cryopreserved primordial germ cells isolated by a newly developed filtration method. World's Poultry Congress in Montreal, Canada, abstract number 808. 2000.

Ukeshima A and Fujimoto T. A fine morphological study of germ cells in asymmetrically developing right and left ovaries of the chick. The Anatomical Record, $230: 378-386.1991$.

Yang GQ and Fujihara N. Long-term proliferation of chicken primordial germ cells cultured in vitro. Journal of Reproduction and Development, 45 : 161-166. 1999a.

Yang GQ and Fujihara N. Survival and proliferation of refined chicken circulating primordial germ cells cultured in vitro. Journal of Reproduction and Development, 45 : 177-181. 1999 b.

Yasuda Y, Tajima A, Fujimoto T and Kuwana T. A method to obtain avian germ-line chimaeras using isolated primordial germ cells. Journal of Reproduction and Fertility, 96 : 521-528. 1992. 